\title{
Ortho-Surgical Management of Open Bite Skeletal Class III Malocclusions with Periodontics Deficiency in Adult Patient: Case Report
}

\author{
Amal El Aouame ${ }^{1 *}$, Lahcen Ousehal ${ }^{1}$ and Kadiri Fatmi ${ }^{2}$ \\ ${ }^{1}$ Department of Dentofacial Orthopedics, Dental University of Casablanca, Morocco \\ ${ }^{2}$ Oral and maxillofacial surgery, Private Practice, Casablanca, Morocco
}

Submission: March 26, 2018; Published: May 29, 2018

*Corresponding author: Amal El Aouame, Department of Dentofacial Orthopedics, Dental University of Casablanca, Morocco, Email: amal.elaouame@gmail.com

\begin{abstract}
It is known that one of the most challenging problems that confront the practicing orthodontist is the treatment of skeletal Class III malocclusion in adult patients. The clinician is faced with the option of either orthodontic camouflage or orthognathic surgery. In severe cases, ortho-surgical treatment is the only guarantor of successful result both functionally and aesthetically. This case report presents the treatment of a Moroccan female patient with open bite skeletal Class III malocclusion and periodontic desease. After combined orthodontic-surgical treatment the result was complete with positive overbite and acceptable occlusion, using a combination of fixed orthodontic appliance treatment as well as the orthognathic surgical management. The patient was satisfied with her new appearance and function.
\end{abstract}

Keywords: Class III malocclusion; Open bite; Orthognathic Surgery; Bimaxillary osteotomy; Orthodontics

\section{Introduction}

Ones of the most complex problems that orthodontics has to manage are skeletal class III malocclusions.

Prevalence of this type of malocclusion is different from a population to another, it goes in Caucasians ranges from 0.8 to $4.0 \%$, to rises up to $12.13 \%$ in Japanese and Chinese populations, whatever in North Indian population, and it's found in up to $3.4 \%$ of the population [1]. Multi factorial causes are incremented in adult and include genetic and/or environmental factors. The characteristics of this malocclusion are mandibular prognathism, maxillary deficiency or both [2]. Studies show that maxillary deficiency is more frequent, accounting for $60 \%$ to $63 \%$ of the causes of this malocclusion [3]. It's known that etiology of skeletal class III malocclusion is closely linked to heredity [4]. According to Litton et al. [4] one third of a group of patients with severe class III malocclusion had a parent with the same problem and one-sixth had an affected sibling. Arnett shows that jaw bases attribute to malocclusion in all three dimensions; this is why the dentoalveolar and soft tissue components should be reviewed $[5,6]$.

At first the skeletal disharmony is detected and confirmed, then clinician must make the differential clinical diagnosis of Class III malocclusion, by verifying occlusal pattern both at Centric Relation (CR) and Intercuspal Position (IP). This maneuver aims to assess the severity of the malocclusion, and define the nature of causes of Class III malocclusion (skeletal, dental malocclusion or functional. Diagnosis is confirmed by lateral cephalograms at the aforementioned occlusal positions [7]. The treatment decision is based on the clinical examination confronted to the cephalometric analysis by assessing the amount of sagittal and vertical discrepancy, dentoalveolar compensations and facial esthetic [8]. To treat this type of malocclusions we can chose one of two options, orthodontic camouflage treatment witch calls on dentoalveolar compensations [9] and orthodontic-surgical treatment which involves correction of the skeletal disharmony [8].

The choice between these two treatment options is made on the basis of a clinical data face cephalometry. The final decision remains dependent on the practitioner's clinical experience and personal preference [10]. In adult Orthognathic surgery and Orthodontic therapy are compliment to each other to achieve the desired results [11]. Accurate clinical examinations followed by the right diagnosis and treatment planning are essential [12]. These complex cases require careful treatment planning, an integrated approach and patient cooperation [13].

The aim of this report is to describe and discuss the option of orthodontic-surgical treatment of Class III skeletal malocclusion in adult patient for reestablishment of a normal occlusion and an adequate facial esthetics. 


\section{Advances in Dentistry \& Oral Health}

\section{Case Report}

Moroccan female patient aged 35 years reported dissatisfaction with her facial and dental appearance associated to functional problems. Facial examination disclosed facial symmetry with malar deficiency, oral closure needed contracture of perioral muscles. The facial profile was concave, with maxillary hyperplasia, a protrusive nasomaxillary area and prominent lower third of the face with a protruded lower lip relative to the upper lip. Smile analyses showed a low smile line with a gingival exposure and a well developed buccal corridors (Figure 1)



Figure 1: Pre-treatment photographs, panoramic radiograph and lateral cephalometric radiograph.

Intraoral examination objectified a narrow maxilla, class III molar and canine relationship, anterior crossbite with lack of overbite and bilateral posterior crossbite, accentuated negative dentoalveolar discrepancy in the maxillary arch. The patient had a pathological periodontal tissue, with bilaterals incisif's diastema and local recessions in the mandible. No other family members were known to have similar abnormalities of the teeth and craniofacial skeleton. Panoramic radiograph (Figure 2) showed horizontal resorption of the bone crests both in the maxilla and the mandible, missing mandibular third molars and retention of the maxillary third one. The postero anterior cephalometric radiograph of the face confirmed skeletal classe III malocclusion with open bite sign's.
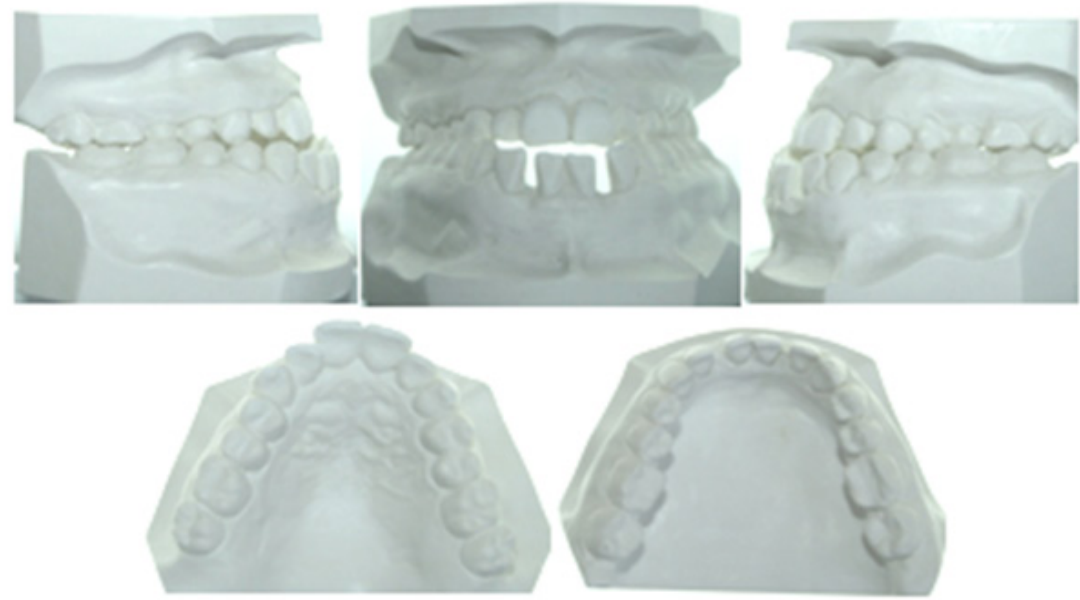

Figure 2: Pre-treatment orthodontic study models. 


\section{Advances in Dentistry \& Oral Health}

Cephalometric analysis revealed a good antero posterior maxillary relationship $\left(\mathrm{SNA}=81^{\circ}\right)$, with the mandible positioned anteriorly to the cranial base $\left(\mathrm{SNB}=87^{\circ}\right)$. The lag bone bases was negative and estimated at $6^{\circ}$, it was accentuated by vertical abnormality due to posterior mandibular rotation. Added to this classical dento-alveolar compensations was observed and expressed in sagittal plan with pro alveolar upper incisive (I/NA= $7 \mathrm{~mm}$ ) and retroalveolar lower incisive (i/NB=3mm) (Table 1). No relevant family and medical history was to note. However, the patient was greatly dissatisfied by her looks and highly positive for the treatment.

Table 1: Cephalometric data.

\begin{tabular}{|c|c|c|c|}
\hline Céphalometry & Objectives & Before Treatment & After Treatment \\
\hline SNA & 820 & 810 & 820 \\
\hline SNB & 800 & 870 & 800 \\
\hline ANB & 20 & -80 & 20 \\
\hline SND & 760 & 790 & 760 \\
\hline I/NA & 220 & 280 & 240 \\
\hline I/NA mm & $4 \mathrm{~mm}$ & $7 \mathrm{~mm}$ & 280 \\
\hline I/NB & 250 & 250 & $4,5 \mathrm{~mm}$ \\
\hline i/NB mm & $4 \mathrm{~mm}$ & 1250 & 1300 \\
\hline I/i & 1310 & $1 \mathrm{~mm}$ & $2 \mathrm{~mm}$ \\
\hline Pog/NB & & 220 & 160 \\
\hline Occ/SN & 140 & 470 & 370 \\
\hline GoGn/SN & 320 & & \\
\hline
\end{tabular}

\section{Treatment plan}

The aim of our treatment was to attain a pleasing profile by improving the relationships of jaw bases. We wanted also to correct crossbite and open bite, individual tooth rotations, make sure that an dequate torque for maxillary and mandibular incisors is achieved and at the same time improve the smile line. To reach these goals, was decided for an orthognathic approach, this treatment included three phases. The first one is the presurgical phase which consists of orthodontic preparation that was essential to correct dental disharmonies with aligning the arches and improving torque of maxillary and mandibular incisors. We initiated with 022 preajusted edgewise appliance. The orthodontic treatment was done without premolar exyarctions. Both maxillary and mandibular arches were aligned using flexible wires NiTi archs which were followed by progressive heavy arch. A quad helix was bonded on the maxillary arch to obtain transversal alveolar expansion (Figure 3). The second phase is jaw surgery. Bilateral sagittal split osteotomy was performed to setback the mandible by $5 \mathrm{~mm}$. LeFort I surgical procedure was carried out as decided and the maxilla was repositioned $3 \mathrm{~mm}$ superiorly.

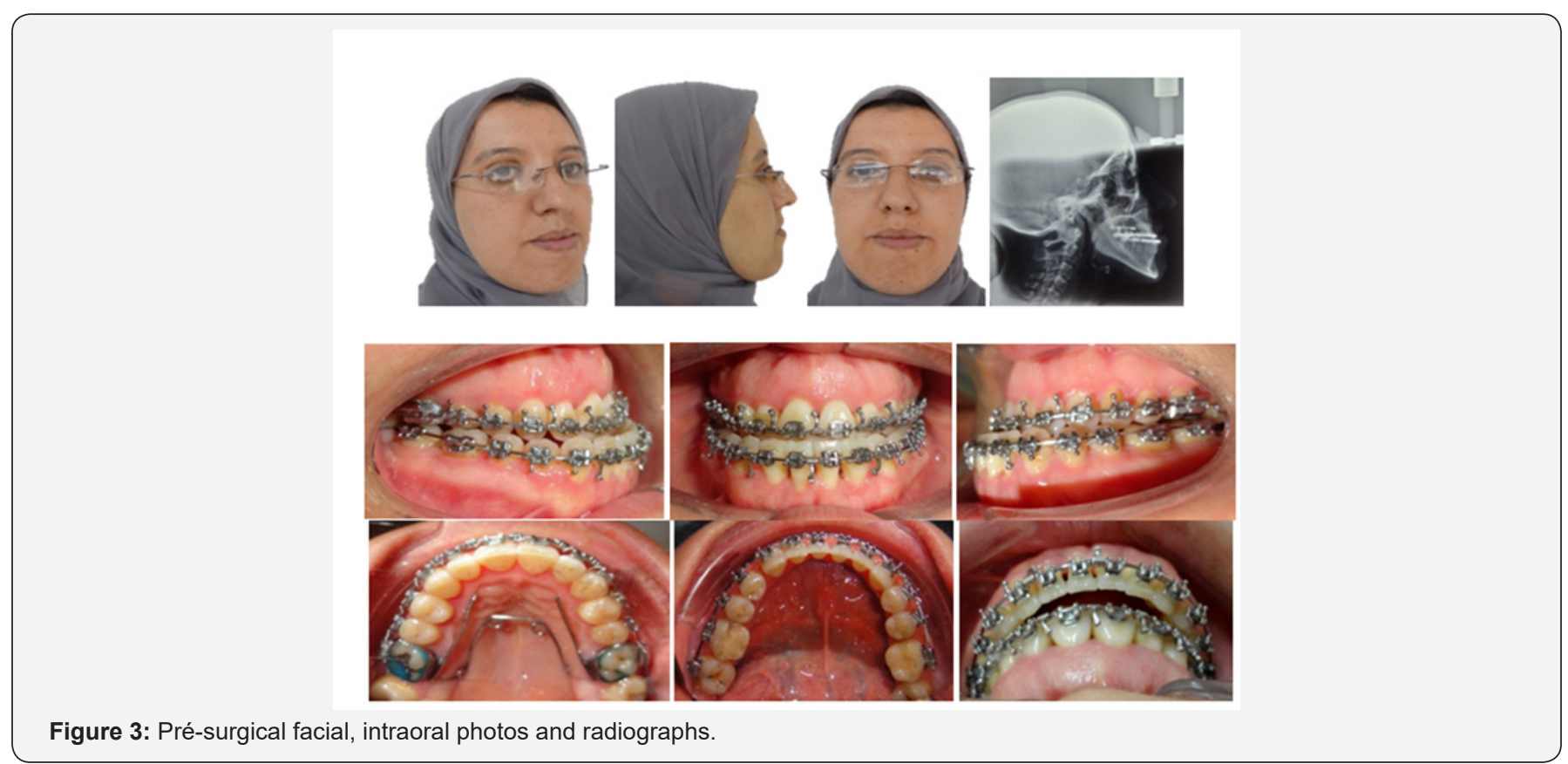




\section{Advances in Dentistry \& Oral Health}

In the aim to stabilize the mandibular, a rigid fixation was used. Finally, a post-surgical phase has been, it's an orthodontic phase to achieve final desired tooth interdigitation using wires and settling elastics (Figure 4).
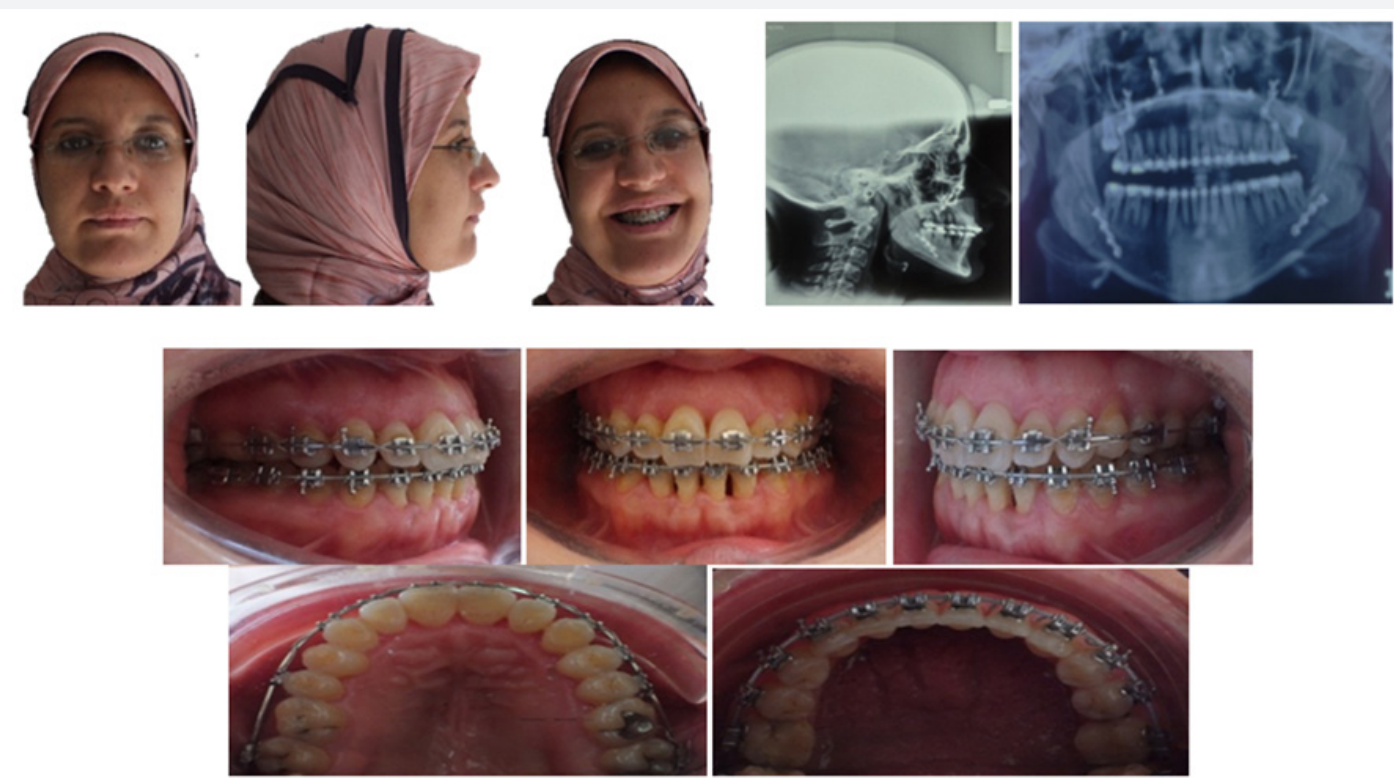

Figure 4: Post-surgical facial, intraoral photos and radiographs.

\section{Treatment results}

After combined orthodontic-surgical treatment, it was observed functional occlusion, normal overjet and overbite, adequate intercuspation with coincident midlines, and normal lateral and protrusive excursions.
The post-treatment radiograph revealed no periodontal bone loss, acceptable root parallelism of the newly positioned incisors and canines (Figure 5). The cephalometric data showed that the sagital skeletal relationship was corrected from Class III to Normal and the mandiblular plane was maintained (Table 1). The overall treatment duration was 6 months.
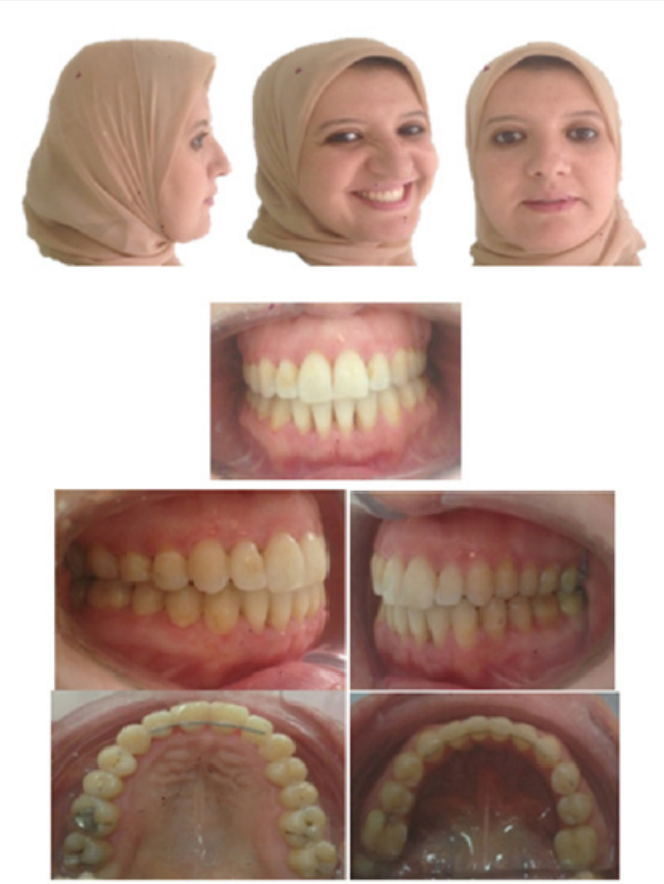

Figure 5: Final extraoral, intraoral photographs and radiographs. 


\section{Discussion}

Skeletal class III malocclusion in adult is characterized by a rich clinical table, which involves many esthetic and functional prejudices, [14] a good comprehension of the components of this malocclusion conditions the establishment of an accurate and effective treatment plan [15]. To treat this type of malocclusion, the clinician can chose between two options, orthodontic camouflage and orthognathic surgery. The use of the surgery requires that the clinician after evaluating the patient's face, deduce that facial esthetics is deficient, which imply that orthodontic treatment alone is insufficient to achieve a successful result.

Many authors agree on the fact that in adult patient who present with ful fledgest class III malocclusion, combined orthosurgical management remains the only option $[4,16,17]$. For limit cases called "bordline, the choice of the appropriate option can be difficult to make. Many studies have been destined to identify criteria of distinguishing the mean value of indicators of treatment choice, especially the cephalometric ones $[15,18]$. According to Cassindy [19] borderline Class III can be treated by orthodontic or surgical treatment, in the base of moderate skeletal discrepancies they involves [19].

In our case, patient presented severe class III malocclusion, with many esthetics and functional problems.

Skeletal parameters were sounded on the facial plane with esthetic disgrace. The therapy of choice to correct the skeletal discrepancy was ortho-surgical treatment through dental decompensation. Orthodontically, it was easy to achieve negative overjet by repositioning the maxillary anterior teeth and closing spaces at the mandible. Patient was informed about aesthetic prejudice than result of the lag aggravation before surgery; she was also made aware of the need for combined surgery. Bilateral sagittal split osteotomy was performed to setback the mandible by $5 \mathrm{~mm}$, we associate le- Forte I surgical procedure, to reposition the maxilla $3 \mathrm{~mm}$ superiorly and correct vertical prejudice.

Referring to Eckhardt \& Cherackal [1,20] bimaxillary osteotomy, comparing to one-jaw osteotomies, offers a greater potential to modify anterior face height, what is heard on the soft tissues. This is why it's justified in patients, such as in this case, in the aim to improve excessive vertical dimension of the lower face $[1,20]$. Clinical success after orthognathic therapy can be defined as a combination of following factors: patient (and patient's family) satisfaction, Correct static and functional occlusion, patient comfort when chewing no pain in the temporomandibular joint and stability of the result in long term [16].

In terms of stability, in 2-jaw surgery, there is better control of ramus inclination and less relapse related to this, but upward movement of the maxilla that allows the chin to rotate upward and forward brings its total forward movement to about the same level as with mandonly surgery [4]. When upward and forward movements of the maxilla are combined with lower border ramus osteotomies, thus prevent excessive forward rotation of the mandible and garant the excellent postsurgical stability $[16,21]$.

Mobarak et al. [21] assessed long trem changes in soft tissue profile following mandibular setback surgery and deduced that mandibular setback surgery is a stable procedure and if relapse occurs, it appears in first six months postoperatively [22-25]. Bailey et al. [26] evaluated long term soft tissue changes after orthodontic and surgical corrections of skeletal class III malocclusions and concluded that class III patients are less stable during first year after surgery but show fewer changes in hard and soft tissue measurements beyond that point [26]. In their retrospective cephalometric study extended over a period of 5 years, L'Tanya J et al. [27] show those skeletal Class III adult patients treated by ortho-surgery show minimal change in soft tissues in post-surgery [27].

\section{Conclusion}

High Class III certainly is a great challenge to orthodontist and constitutes the greatest cause of facial deformity among all types of malocclusions. Success in the management of such malocclusion is conditioned by a proper diagnosis and treatment planning. In adult with a severe discrepancy, combined orthosurgical approaches is the only way to achieve successful results. It demure a stable procedure, however relapse may be due to faculty planning, faulty or postsurgical growth which is avoided in adult patients. In our case the patient and her legal guardians were very pleased with the final result, which considerably improved her self-esteem. In contrast long term follow up demure essential.

\section{Ethical Statement}

The patient has been consented and approved the inclusion of her case and photographs in this scientific purpose.

\section{References}

1. Cherackal GJ, Eapen T, Akhilesh P (2013) Combined Orthodontic and Surgical Approach in the Correction of a Class III Skeletal Malocclusion with Mandibular Prognathism and Vertical Maxillary Excess Using Bimaxillary Osteotomy, Case Reports in Dentistry p. 12.

2. Delaire J (1997) Maxillary development revisited: relevance to the orthopedic treatment of Class III malocclusions. Eur J Orthod 19(3): 289-311.

3. Turley P (1988) Orthopedic correction of Class III malocclusion with palatal expansion and custom protaction headgear. J Clin Orthod 22(5): 314-325.

4. Proffit WR, Ceib KP, Timothy A Turvey (2012) Stability after mandibular setback: mandible-only vs. two-jaw surgery $\mathrm{j}$ oral maxillofac surg 70(7): e408-e414.

5. Arnett GW, Jelic JS, Kim J, Cummings DR, Beress A, et al. (1999) Soft tissue cephalometric analysis: diagnosis and treatment planning of dentofacial deformity. Am J Orthod Dentofacial orthop 116(3): 239253.

6. Arnett GW, McLaughlin R (2004) Facial and dental planning for orthodontists and oral surgeons. Mosby Elsevier, London.

7. Rabie $A B, G u$ Y (2000) Diagnostic criteria for pseudo-Class III malocclusion. Am J Orthod Dentofacial Orthop 117(1): 1-9. 
8. Schuster G, Lux CJ, Stellzig-Eisenhauer A (2003) Children with Class III malocclusion: development of multivariate statistical models to predict future need for orthognathic surgery.Angle Orthod 73: 136-145.

9. Baron P (1993) Therapeutique orthodontique ou chirurgicale des Classes III squelettiques: elements de decision. Rev Orthop Dento Faciale 27: 305-314.

10. Stellzig Eisenhauer A, Lux CJ, Schuster G (2002) Treatment decision in adult patients with Class III malocclusion: orthodontic therapy or orthognathic surgery? Am J Orthod Dentofacial Orthop 122(1): 27-37.

11. Wilmot DR (1981) Soft tissue profile changes following correction of Class III malocclusion by mandibular surgery. Br J Orthod 8(4): 175181.

12. Ravi MS, Shetty Nillan K, Prasad Rajendra B (2012) Orthodonticssurgical combinaition therapy for class III skeletal malocclusion; Contemporary Clinical Dentistry 3(1): 78-82.

13. Katiyar R, Singh GK, Mehrotra D, Singh A (2010) Surgical-orthodontic treatment of a skeletal class III malocclusion. Natl J Maxillofac Surg 1(2): 143-149.

14. Tompach PC, Wheeler JJ, Fridrich KL (1995) Orthodontic considerations in orthognathic surgery. Int J Adult Orthodon Orthoganth Surg 10(2): 97-107.

15. Takahashi H, Furuta H, Moriyama S (2009) Assessment of three bilateral sagittal split osteotomy techniques with respect to mandibular biomechanical stability by experimental study and finite element analysis simulation; Med Bull Fukuoka Univ 36: 181-92.

16. Kamat NV, Chandra PK, Timble A, Godinho A (2009) Ortho-surgical Management of Class III Malocclusion in Identical Twins - Care Report J Ind Orthod Soc 43(1): 23-39.

17. Phillips C, Proffit WR (2003) Phycosocial aspects of dentofacial deformities and its treatment. In: Proffit WR, Fields HW, Sarver DM (Eds.), Contemporary; treatment of dentofacial deformity, Mosby, St Louis, USA.
18. Rabie ABM, Wong RWK, Min GU (2008) Treatment in borderline Class III malocclusion: orthodontic camouflage (extraction) versus orthognathic surgery. Open Dent J 2: 38-48.

19. Cassidy Jr DW, Herbosa EG, Rotskoff KS, Johnston Jr LE (1993) A comparison of surgery and orthodontics in "borderline" adults with Class II, division 1 malocclusions. Am J Orthod; Dentofacial Orthop 104(5): 455-470.

20. Eckhardt CE, Cunningham JS (2004) How predictable is orthognathic surgery? European Journal of Orthodontics 26(3): 303-309.

21. Gallego RD, Llamas Carrera JM, Torres Lagares D, Paredes V, Espinar E et al. (2012) Long-term stability of surgical-orthodontic correction of class III malocclusions with long-face syndrome. Med Oral Patol Oral Cir Bucal 17(3): e435-e441.

22. Edward Ellis III, James A McNamara Jr (1984) Components of adult Class III open-bite malocclusion American Journal of Orthodontics 86(4): 277-290.

23. Ishii N, Deguchi T, Hunt N (2002) Craniofacial difference between Japanese and british Caucasian females with a skeletal class III malocclusion.Eur J Orthod 24(5): 493-499.

24. Baccetti T, Reyes BC, McNamara JA Jr (2005) Gender differences in Class III malocclusion. Angle Orthod 75(4): 510-520.

25. Proffit WR, Phillips C, Sarver DM (2007) Tratamento cirúrgico e ortodônticocombinados. In: Proffit WR, Fields HW, Sarver DM (Eds.), Ortodontiacontemporânea. Rio de Janeiro, Mosby, USA.

26. L'Tanya J Baileya, Amy Joslin Doverb, William R Proffit (2007) Longterm Soft Tissue Changes after Orthodontic and Surgical Corrections of Skeletal Class III Malocclusions, Angle Orthod 77(3): 389-396.

27. Mendiratta A, Mesquita AAM, Kamat NV, Dhupar V (2014) Orthosurgical Management of a Severe Class III Malocclusion. J Ind Orthod Soc 48(4): 273-279.

\section{Your next submission with Juniper Publishers will reach you the below assets}

- Quality Editorial service

- Swift Peer Review

- Reprints availability

- E-prints Service

- Manuscript Podcast for convenient understanding

- Global attainment for your research

- Manuscript accessibility in different formats

( Pdf, E-pub, Full Text, Audio)

- Unceasing customer service

Track the below URL for one-step submission https://juniperpublishers.com/online-submission.php 